\title{
Converting mesophilic upflow sludge blanket (UASB) reactors to thermophilic by applying axenic methanogenic culture bioaugmentation
}

Zhu, Xinyu; Treu, Laura; Kougias, Panagiotis G.; Campanaro, Stefano; Angelidaki, Irini

Published in:

Chemical Engineering Journal

Link to article, DOI:

10.1016/j.cej.2017.09.113

Publication date:

2018

Document Version

Peer reviewed version

Link back to DTU Orbit

Citation (APA):

Zhu, X., Treu, L., Kougias, P. G., Campanaro, S., \& Angelidaki, I. (2018). Converting mesophilic upflow sludge blanket (UASB) reactors to thermophilic by applying axenic methanogenic culture bioaugmentation. Chemical Engineering Journal, 332, 508-516. https://doi.org/10.1016/j.cej.2017.09.113

\section{General rights}

Copyright and moral rights for the publications made accessible in the public portal are retained by the authors and/or other copyright owners and it is a condition of accessing publications that users recognise and abide by the legal requirements associated with these rights.

- Users may download and print one copy of any publication from the public portal for the purpose of private study or research.

- You may not further distribute the material or use it for any profit-making activity or commercial gain

- You may freely distribute the URL identifying the publication in the public portal 


\section{Accepted Manuscript}

Converting mesophilic upflow sludge blanket (UASB) reactors to thermophilic by applying axenic methanogenic culture bioaugmentation

Xinyu Zhu, Laura Treu, Panagiotis G. Kougias, Stefano Campanaro, Irini Angelidaki

PII: S1385-8947(17)31610-8

DOI: http://dx.doi.org/10.1016/j.cej.2017.09.113

Reference: CEJ 17698

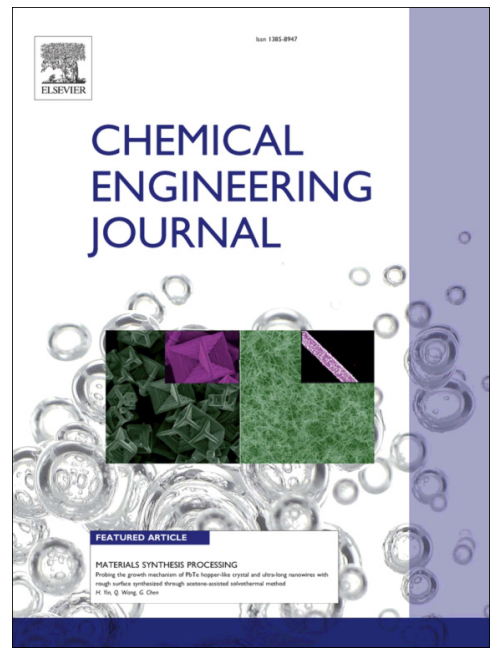

To appear in:

Chemical Engineering Journal

Received Date:

10 July 2017

Revised Date:

15 September 2017

Accepted Date:

19 September 2017

Please cite this article as: X. Zhu, L. Treu, P.G. Kougias, S. Campanaro, I. Angelidaki, Converting mesophilic upflow sludge blanket (UASB) reactors to thermophilic by applying axenic methanogenic culture bioaugmentation, Chemical Engineering Journal (2017), doi: http://dx.doi.org/10.1016/j.cej.2017.09.113

This is a PDF file of an unedited manuscript that has been accepted for publication. As a service to our customers we are providing this early version of the manuscript. The manuscript will undergo copyediting, typesetting, and review of the resulting proof before it is published in its final form. Please note that during the production process errors may be discovered which could affect the content, and all legal disclaimers that apply to the journal pertain. 


\section{Converting mesophilic upflow sludge blanket (UASB) reactors to}

\section{thermophilic by applying axenic methanogenic culture bioaugmentation}

Xinyu Zhu ${ }^{a}$, Laura Treu ${ }^{\text {ab }}$, Panagiotis G. Kougias ${ }^{\mathrm{a}^{*}}$, Stefano Campanaro ${ }^{\mathrm{c}}$ and Irini Angelidaki $^{\mathrm{a}}$

${ }^{a}$ Department of Environmental Engineering, Technical University of Denmark, Kgs. Lyngby, DK-2800, Denmark

${ }^{\mathrm{b}}$ Department of Agronomy, Food, Natural resources, Animal and Environment (DAFNAE), University of Padova, Viale dell'Università, 16, 35020 Legnaro (Padova), Italy

'Department of Biology, University of Padova, Via U. Bassi 58/b, 35121, Padova Italy

* Corresponding author and address:

Panagiotis G. Kougias

Department of Environmental Engineering,

Technical University of Denmark

Bld 113, 2800 Lyngby

Denmark

E-mail address: panak@env.dtu.dk,

Tel.: +45 4525 1454; fax: +45 45932850 


\begin{abstract}
The application of thermophilic conditions in anaerobic digesters leads to higher methane production rates and better sanitation of the effluents compared to mesophilic operation. However, an increase in operational temperature is challenging due to the tremendous selective pressure imposed on the microbial consortium. The adaptation of microbial community to a new environment or condition can be accelerated by a process known as "bioaugmentation" or "microbial community manipulation", during which exogenous microorganisms harbouring specific metabolic activities are introduced to the reactor. The aim of the current study was to rapidly convert the operational temperature of up-flow anaerobic sludge blanket (UASB) reactors from mesophilic to thermophilic conditions by applying microbial community manipulation techniques. Three different bioaugmentation strategies were compared and it was proven that the injection of axenic methanogenic culture was the most efficient approach leading to improved biomethanation process with $40 \%$ higher methane production rate compared to the control reactor. Microbial community analyses revealed that during bioaugmentation, the exogenous hydrogenotrophic methanogen could be encapsulated in granular structures and concomitantly promote the growth of syntrophic fatty acid oxidizing bacteria. The results derived from the current study indicated that microbial community manipulation is an efficient alternative method to speed up transition of UASB reactors from mesophilic to thermophilic conditions.
\end{abstract}

\title{
Keywords
}

Upflow Anaerobic Sludge Blanket; reactor; granule; bioaugmentation; 16S rRNA gene; axenic culture 


\section{Introduction}

Anaerobic digestion (AD) is a popular technology for simultaneous production of energy and treatment of wastewaters. Various reactor types and configurations have been developed in order to increase the efficiency of the process and to be able to utilize a wide variety of substrates. Up-flow anaerobic sludge blanket (UASB) reactors are extensively used to treat high strength liquid wastes such as leachate from food waste, cheese whey and textile dyeing wastewater [1-3]. In a UASB reactor, the liquid waste flows through the sludge bed at a significantly shorter hydraulic retention times (HRT) compared to the growth rates of key microorganisms for the biomethanation process. The granular sludge with excellent settling properties confines the active microbes and prevents them from washout [4]. UASB reactors are widely used in tropic countries where the reactors operate at ambient temperature $\left(21-24{ }^{\circ} \mathrm{C}\right)$ or at mesophilic conditions $[5,6]$.

It is postulated that the conversion rate increases with temperature in $\mathrm{AD}$ process [7]. Nevertheless, especially in applications where UASB reactors are used, it is extremely difficult to find thermophilic granular sludge. This is mainly because most of the UASB reactors are operated at mesophilic conditions to avoid heating costs and to increase the tolerance of the process towards specific inhibitors such oleate [8]. Previous researchers analysed the process stability during temperature transition from mesophilic to thermophilic operation; however, the outcomes were inconclusive $[9,10]$. Results showed that in specific cases the methane production was inhibited without providing an obvious explanation regarding this failure. Denaturing gradient gel electrophoresis (DGGE) of 16s rRNA gene was applied to analyse the granular microbial community changes from mesophilic to thermophilic treatment of palm oil mill effluent, and the results suggested significant differences in microbiota compositions [11]. However, the microbial community was not explored quantitatively and comprehensively due to the technical limitations of DGGE technique. Recent studies based on high throughput amplicon sequencing remarked that 
during temperature transition, the thermophilic bacterial community evolved spontaneously in liquid phase of UASB reactors and were found inhabiting in the granular structures [12]. However, it was demonstrated that the thermophilic archaeal group grew slowly and concomitantly led to process imbalance [13].

The key postulate of successful temperature conversion is the ubiquity of thermophiles. Therefore, the most commonly used practice in biogas reactors involves a stepwise increment of the operating temperature, which allows a spontaneous but slow microbial community transition. A method to accelerate the microbial adaptation into new or extreme conditions is known as "bioaugmentation" or "microbial community manipulation" and relies on the provision of exogenous microbial consortia into certain microbial ecosystems to manipulate the existing metabolic activities towards a desired effect or process. Recently, the bioaugmentation strategies are gaining increased attention in different $\mathrm{AD}$ applications. For example, bioaugmentation was used to increase hydrolysis of cellulose [14], overcome ammonia inhibition [15] and restore methane production from overloaded reactor [16]. Microbes encoding proteins involved in crucial steps of biomethanation were injected into biogas reactors leading to significant enhancement of methane production. One important consideration about bioaugmentation in continuous reactor operations is the duration of the bioaugmentation effect, which is related to the maintenance and proliferation of the exogenous microbes inside the reactor. It is often reported that the positive bioaugmentation effect occurrs for a limited time period after the inoculation due to the wash out of the exogenous strains $[14,17]$. This obstacle could potentially be overcome in sludge retaining reactors due to the fact that the microbes can be immobilised into the granules, and thus, stay in the reactor for longer periods.

In the current study, three bioaugmentation strategies were examined by comparing both reactor performance and microbial community dynamics. Two laboratory-scale mesophilic UASB reactors 
were successfully changed to thermophilic operation with and without applying selected bioaugmentation. Methane production rate and yield were monitored in order to evaluate the process enhancement, and high throughput amplicons sequencing was employed to reveal the microbial dynamics in the granules. The outcomes of the current work allowed the proposal of an alternative method to enhance biomethanation in UASB reactors and also provided insights regarding the shifts of microbial composition during process optimization.

\section{Materials and methods}

\subsection{Characteristics of substrate and granules}

Mesophilic granules used in this study were obtained from a full scale UASB reactor of a wastewater treatment plant (Colsen) processing potato juice in Netherlands. The granules were stored at $4{ }^{\circ} \mathrm{C}$ and moved to room temperature for 24 hours before use. Potato juice used as substrate was obtained from potato-starch processing factory (Karup Kartoffelmelfabrik, Denmark) in two batches. Batch 1 was used as substrate in the experiment related to the selection of bioaugmentation strategy and Batch 2 was used during biomethanation enhancement by thermophilic operation and bioaugmentation. The raw potato juice was diluted with distilled water before usage in order to achieve the desired the organic loading rate (OLR) and HRT. The characteristics of raw and diluted potato juice are presented in Table 1.

\subsection{Experiment 1-testing various bioaugmentation strategies}

Three different bioaugmentation strategies were investigated using lab scale UASB reactors with working volume of $1.4 \mathrm{~L}$. The reactor configuration was previously described by Zhu et al. [13]. Briefly, the liquid feedstock was supplied from the bottom of the reactor every 6 hours according to the designed HRTs and OLRs. In addition to the feedstock influent, internal liquid 
recirculation was applied to create an up flow velocity of $2.2 \mathrm{~m} / \mathrm{h}$, providing efficient mixing of the feedstock and hydraulic condition for granular structure maintenance. Initially, four UASB reactors were inoculated with $600 \mathrm{~mL}$ mesophilic granular sludge and $800 \mathrm{~mL}$ basal anaerobic (BA) medium [18]. The reactors operated at $55^{\circ} \mathrm{C}$ and the bioaugmentation was performed at the first day of operation. One reactor operated without any bioaugmentation practice serving as control (Control 1).

In Strategy 1, the practice previously proposed to develop thermophilic adapted granules by replacing the $800 \mathrm{~mL} \mathrm{BA}$ medium with $\mathrm{AD}$ digestate was followed [19]. The digestate used for bioaugmentation was obtained from a conventional lab scale continuous stirring tank biogas reactor (CSTR) treating cattle manure at $55^{\circ} \mathrm{C}$. The rationale beyond this strategy was that the digestate from CSTR would provide a "complete" thermophilic microbial consortium mediating the entire $\mathrm{AD}$ process from hydrolysis to methanogenesis. Besides the biotic parameters i.e. the active methanogenic microbial community, digestate from cattle manure degradation provides abiotic enhancement, such as the necessary nutrients for optimal microbial growth, the high $\mathrm{pH}$ buffer capacity and the absence of substances that could inhibit the biomethanation process (e.g. high ammonia or fatty acid concentration). It is expected that the abiotic benefits will be gradually weakened with long operation due to the wash out of digestate; however, it was hypothesized that till that time an adapted microbial consortium would be fully shaped. Strategy 2 relied on the injection of $40 \mathrm{~mL}$ of $\mathrm{AD}$ digestate (same origin as described previously) into the UASB reactor for 6 consecutive days. During the bioaugmentation period the reactor was daily fed with $40 \mathrm{~mL}$ of potato juice to proliferate specialised microbes for substrate degradation. Comparing with previous strategy, the low proportion of AD digestate in the liquid phase limited the abiotic enhancement and therefore we were able to focus our evaluation on the manipulation of microbial community composition. Strategy 3 relied on the injection of a specific axenic thermophilic methanogenic 
culture in the liquid phase of the UASB reactor. The daily injected amount of axenic methanogens $(40 \mathrm{~mL})$ consisted of isovolume archaeal culture containing Methanothermobacter thermautotrophicus (DSM No. 3720) and Methanosarcina thermophila (DSM No. 1825). The two strains were chosen based on their ubiquity in AD system and their metabolic capacities to cover the most known methanogenic pathways, namely acetoclastic and hydrogenotrophic. The supplied archaeal strains were obtained from Leibniz Institute DSMZ-German Collection of Microorganisms and Cell Cultures and were always injected into the reactor under exponential growth phase. The cultivation procedure was previously described by Tsapekos et al.[14]. The composition of the cultivation media and growth curve for both strains are presented in Supplementary Information (Table S1, Table S2, Fig. S1 and Fig. S2). The cell yields in both cultures were assumed proportional to methane production and the biomass concentrations were calculated from substratespecific coefficient: $\mathrm{Y}_{\mathrm{H} 2+\mathrm{CO}_{2}}=8.7 \mathrm{mg}$ dry cell mass $/ \mathrm{mmol} \mathrm{CH}_{4}$ and $\mathrm{Y}_{\text {acetate }}=2.1 \mathrm{mg}$ dry cell mass/ mmol $\mathrm{CH}_{4}$ [20]. As a result, each bioaugmentation portion (40 mL) contained $3.8 \mathrm{mg} M$.

thermautotrophicus and $5.0 \mathrm{mg}$ M. thermophila as dry cell mass. The bioaugmentation period lasted for 6 days and the operation details for each strategy are listed in Table 2. In order to evaluate effect of bioaugmentation, we operated the reactor using potato juice as substrate for 21 days i.e. 3 HRTs at the OLR of $4 \mathrm{gVS} / \mathrm{L}-$ reactor.day after the bioaugmentation.

\subsection{Experiment 2-elucidation of the microbial composition alterations as a result of biomethanation with axenic cultures}

The enhancement and persistence of bioaugmentation was tested in 2 laboratory scale UASB reactors, each one having a working volume of $1.2 \mathrm{~L}$. The reactor configuration was previously described by Fang et al. [6]. Initially, the reactors operated at mesophilic conditions $\left(37^{\circ} \mathrm{C}\right)$ for 27 days until the achievement of stable (less than $10 \%$ variance for $1 \mathrm{HRT}$ ) methane production. The 
OLR and HRT were $3 \mathrm{gVS} / \mathrm{L}-$ reactor.day and 8 days respectively. Subsequently, the operational temperature was changed to $55^{\circ} \mathrm{C}$ and one reactor was bioaugmented according to the Strategy 3 , while the same amount of BA medium was added to the other reactor serving as control. Only bioaugmentation by Strategy 3 was tested, because it is considered as the best among all tested strategies due to the highest methane yield achieved in the former experiment. After the bioaugmentation period, the feeding was stopped for a week in order to avoid microbial wash out and to establish a new stable thermophilic microbial community. Potato juice was gradually added in the reactor at day 43 , and the reactor started operating at the same OLR and HRT as during the mesophilic operation from day 45. Once steady state was achieved, the OLR was further stepwise increased to $4 \mathrm{gVS} / \mathrm{L}$-reactor.day and $8 \mathrm{gVS} / \mathrm{L}$-reactor.day by reducing the HRT to 6 and 3 days at day 76 and 91, respectively. Previous studies showed that potato juice has extremely low alkalinity, and extra $\mathrm{pH}$ buffering is necessary to assist methanogenic activity under thermophilic conditions. Therefore, the substrate was supplemented with sodium bicarbonate at concentration of $2.6 \mathrm{~g} / \mathrm{L}$ to favour a mild transition from mesophilic to thermophilic operation.

\subsection{Analytical methods}

Total solids, volatile solids, total nitrogen and total ammonia of potato juice were determined according to APHA standard methods for the examination of water and wastewater [21]. The daily biogas production was quantified using a water replacement gas meter and methane concentration was measured using a gas chromatograph (Mikrolab, Aarhus A/S, Denmark), equipped with a thermal conductivity detector (TCD) as previously described [22]. Other digestion products including VFA and ethanol concentration were measured using a gas chromatograph (Shimadzu GC-2010 AF, Kyoto, Japan), equipped with a flame ionization detector (FID) as described by Kougias et al. [22]. All determinations and measurements were done in triplicate samples. The 
theoretical methane equivalent of intermediates (VFAs and alcohols) was determined assuming that all organic material will be converted to $\mathrm{CH}_{4}$ and $\mathrm{CO}_{2}$ and calculated from the following equation [23].

$$
C_{n} H_{a} O_{b}+\left(n-\frac{a}{4}-\frac{b}{2}\right) H_{2} O \rightarrow\left(\frac{n}{2}+\frac{a}{8}-\frac{b}{4}\right) C H_{4}+\left(\frac{n}{2}-\frac{a}{8}+\frac{b}{4}\right) C_{2}
$$

\subsection{Samples collection, DNA extraction and sequencing analysis}

Triplicate samples from all the reactor configurations at various time points were collected in order to analyse the microbial communities. During the experiment 1, 5 granular samples were obtained from mesophilic granules (MG) and immediately after each bioaugmentation strategy (Control 1, Strategy 1, Strategy 2 and Strategy 3). During the experiment 2, 3 granule samples were obtained at steady state of mesophilic operation (MO), thermophilic operation with bioaugmentation of axenic methanogens (TA) and thermophilic operation without bioaugmentation (Control 2). All granular samples were obtained from the centre of the sludge bed reactor and were washed three times with phosphate buffered saline buffer (1 M, pH 7.4) in order to exclude the suspended biomass. DNA extraction was performed using PowerSoil® DNA Isolation Kit (MoBio PowerSoil, Carlsbad,CA USA) with an additional phenol cleaning step in order to improve DNA purification [24]. Universal primers 515F/806R were used to amplify the V4 region of $16 \mathrm{~S}$ rRNA gene and the amplicons were sequenced using MiSeq desktop sequencer at Ramaciotti Centre for Genomics (Sydney, Australia). Raw reads were deposited in Sequence Read Archive (SRA) database (http://www.ncbi.nlm.nih.gov/sra) under the ID PRJNA327299.

OTU clustering and taxonomy identification were performed using CLC Workbench software (V.8.0.2) equipped with the Microbial genomics module plugin as previously described [13]. Only OTUs in the top deciles $\left(90^{\text {th }}\right.$ percentile) of the total community were discussed in the present study. Principal Coordinate Analysis (PCoA) was performed using the vegan-package implemented in R 
software [25]. Bray-Curtis index was calculated with 'vegdist' function and the distance matrix was further visualized by Classical (Metric) Multidimensional Scaling ('cmdscale') with two dimensions. Significant differences in microbial community compositions were identified with ttests using STAMP software [26]. Microbial relative abundance and dynamics of selected taxa were visualized with a heatmap using Multi-Experiment Viewer [27]. A selection of the representative OTUs of specific taxa were chosen for discussion and the taxonomical assignments of sequences were verified in comparison with NCBI 16S ribosomal RNA database using Megablast [28].

\section{Results and Discussion}

\subsection{Comparison and selection of bioaugmentation strategy}

After bioaugmentation, the integrity of granular sludge structure was maintained in Control 1, Strategy 2 and Strategy 3. On contrary the granules in the reactor, where the Strategy 1 was applied, were disintegrated. This phenomenon can be probably explained by the high density of the chosen AD digestate which did not allow the sludge bed to settle properly and to maintain the granular structure under the applied hydraulic conditions. The results of methane yield after bioaugmentation showed that the reactor performance was significantly influenced by the different bioaugmentation strategies (Fig. 1). Moreover, severe process imbalances, such as VFAs and alcohol accumulation, were recorded in the control reactor suggesting an absolute necessity of bioaugmentation to achieve rapid biomethanation start-up (Supplementary information Table S3).

Strategy 1 strongly enhanced methane production due to exogenous microbial consortium provided by AD digestate. Specifically, substantial methane production was observed from the day 4 and methane yields were maintained at $272.9 \pm 36.5 \mathrm{CH}_{4} \mathrm{~mL} / \mathrm{g}$ VS until day 15 (approximately 2 HRT). However, this enhancement effect could not persist and the methane yield decreased significantly after a period of 2 HRTs. The drop of methane yield can be attributed to the disintegration of granular sludge and to the wash out of active methanogens. Immobilization of 
active microbial consortium in granular structures is essential for UASB reactor operation, and else the effective microbes will be washed out at the relatively short HRTs applied in UASB reactors [29]. Therefore Strategy 1 was not selected for further studies.

Strategy 2 used the same AD digestate as Strategy 1, but the digestate was injected to the reactor at a smaller dosage. In this practice 5\% AD digestate (vol/vol) was added into the UASB reactor for 6 consecutive days. Comparing to the previous strategy (100\% AD digestate from the first day), the current treatment led to a limited abiotic enhancement, i.e. nutrition and $\mathrm{pH}$ buffer capacity. Nevertheless, the putative biotic enhancement would persist if the thermophilic methanogenic microbes residing in $\mathrm{AD}$ digestate managed to proliferate in granular sludge. However, in fact, this bioaugmentation strategy led to an extremely inefficient methanogenic process (Fig. 1a); and the methane production accounted only for approximately $9 \%$ of methane equivalent of all digestion products, indicating the majority substrates were transformed to intermediate products (Fig. 1b). The $\mathrm{pH}$ values during the operation dropped to 5.8 due to VFA accumulation and low alkalinity of the substrate [30]. Consequently, the low $\mathrm{pH}$ promoted alcohol production and inhibited the methanogenic microbial community in the granules.

Strategy 3 targeted specifically the last step of digestion, i.e. methanogenesis, by adding axenic hydrogenotrophic and acetoclastic methanogenic cultures, namely M. thermautotrophicus and $M$. thermophila. The exogenous methanogens significantly enhanced the biomethanation process and similar methane yield to Strategy 1 was observed $\left(240.1 \pm 29.5 \mathrm{CH}_{4} \mathrm{~mL} / \mathrm{g} \mathrm{VS}\right)$. Concomitantly, methane was the main digestion product accounting for $62 \%$ of the total digestion process outcomes (Fig. 1b).

\subsection{Microbial insights of bioaugmentation strategies}


By comparing the profiles of microbial communities residing in the granules, it was possible to gain insights into the effect of the different bioaugmentation strategies applied. PCoA analysis showed dramatic changes in microbial composition during temperature transition regardless of bioaugmentation (marked in black arrow in Fig 2a). Besides, different bioaugmentation strategies also led to the formation of distinct consortia (marked in red arrows in Fig. 2a). The relatively more minor differences imposed by bioaugmentation compared to temperature transition suggested that the exogenous microbes were compatible with the indigenous communities and did not outcompete the ones that spontaneously increased during temperature transition. The injection of the digestate (Strategy 2) led to a significant increase in relative abundance of 7 bacterial taxa compared to Control 1. However, thermophilic methanogens did not increase significantly indicating that they were not retained by granular structures (Fig. 2b). The most substantial change in the microbial composition was the increase of Clostridium genus. The representative OTU was found to be $100 \%$ similar to a thermophilic butyrate-producing bacterium, namely Clostridium thermopalmarium [31]. The result was in accordance with the high proportion of butyrate recorded among the digestion products. Regarding Strategy 3, two axenic methanogenic strains were introduced, but only $M$. thermautotrophicus was found to be significantly increased compared to the Control (Fig. 2c). The survival of exogenous methanogens depends on the specific ecological niches created by the UASB reactor; however, we cannot be conclusive about the specific mechanisms of different methanogenic strains immobilization based on the present results. It is possible that the hydrogenotrophic methanogenesis was preferable under the current catabolic traits, or alternatively the specific habitat in the reactor was not optimal for the growth of $M$. thermophila strain. In addition to $M$. thermautotrophicus, 7 bacterial taxa were observed in higher relative abundance compared to the Control. The most significant increase was found in the OTU assigned to family D2; whose $16 \mathrm{~S}$ sequence is identical to Thermanaerovibrio velox sequence. This microbial species 
is a thermophilic fermentative bacterium which presumably has syntrophic interaction with $M$. thermautotrophicus due to $\mathrm{H}_{2}$ forming property during substrate utilization [32]. Finally, taxa increasing in abundance in Strategy 3 were different from those of Strategy 2 (Fig. 2d); however, the increased bacteria, although belonging to different taxa in the two strategies, harbour similar catabolism capability, i.e. thermophilic carbohydrate and protein fermentation. The determinative factor that had a direct influence on methane production was the difference in thermophilic methanogens. The results showed that axenic methanogenic culture augmentation significantly increased the relative abundance of $M$. thermautotrophicus, leading to a better methane yield compared to the other strategies.

\subsection{Enhanced methane production with bioaugmentation and thermophilic operation}

The duration of bioaumentation effect of the best bioaugmentation strategy (Strategy 3) was evaluated by operating two additional UASB reactors, namely bioaugmentation and Control 2. A previous study demonstrated that, utilization of potato juice as substrate requires $\mathrm{pH}$ control during temperature transition from mesophilic to thermophilic operation [13]. Therefore, in this experiment bicarbonate was supplemented to the feedstock in order to maintain the $\mathrm{pH}$ levels within the optimum range for methanogenesis. Initially, in both UASB reactors operated at mesophilic conditions $\left(37^{\circ} \mathrm{C}\right)$ and methane was constantly produced at an average rate of $746 \mathrm{~mL} \mathrm{CH} / \mathrm{L}-$ reactor.day (Fig. 3a), accounting for $83 \%$ of the methane equivalent of all digestion products (Fig. 3b). Once steady state conditions had been achieved, the operational temperature was changed to thermophilic $\left(55^{\circ} \mathrm{C}\right)$ at day 27 . Moreover, in one reactor, the bioaugmentation was applied according to Strategy 3; while in the other reactor BA medium was used as control. As a result, the methane production rate decreased to $668 \mathrm{~mL} \mathrm{CH}_{4} / \mathrm{L}$-reactor.day in the control reactor. Although it is postulated that thermophilic $\mathrm{AD}$ has a higher reaction rate compared to the mesophilic operation, 
this innate high rate was probably offset by the slow development of a thermophilic methanogenic microbial consortium during temperature transition. On contrary, the methane production rate of the bioaugmented reactor increased under the same OLR (789 $\mathrm{mL} \mathrm{CH}_{4} / \mathrm{L}-$ reactor.day), and concomitantly methane proportion among total digestion products increased to $92 \%$. The methane production rate in the bioaugmented reactor was $19 \%$ higher in comparison to the control reactor, suggesting that bioaugmentation with axenic methanogens had a positive effect on thermophilic biomethanation process.

Furthermore, the operational HRT of both reactors was sequentially decreased to 6 and 3 days, (i.e. OLR increased to 6 and $8 \mathrm{~g} \mathrm{VS} / \mathrm{L}-$ reactor.day), in order to evaluate the persistence of the positive effect in methanogenesis. In both reactors, higher methane production rates were observed after the reduction of the HRT; however, decreased methane yields were recorded. More specifically, the methane production rates in bioaugmented reactor reached $1014 \mathrm{~mL} \mathrm{CH} / \mathrm{L}$ reactor.day at 6 days $\mathrm{HRT}$ and $1813 \mathrm{~mL} \mathrm{CH}_{4} / \mathrm{L}$-reactor.day at 3 days $\mathrm{HRT}$, accounting for $87 \%$ and $68 \%$ of total digestion products respectively. The methane production rates in bioaugmented reactor were constantly higher than control reactor, especially at short HRTs (i.e. 30\% higher during HRT of 6 days and $41 \%$ higher during HRT of 3 days). The persistent positive effect of bioaugmentation suggested that the exogenous strains were firmly retained in the reactor by granular structure of the sludge $[33,34]$.

\subsection{Microbial community dynamics during temperature transition and bioaugmentation}

The microbial dynamics in granules was analysed by high throughput amplicon sequencing and the results showed that the microbial community composition was deeply influenced by temperature transition and bioaugmentation process. The relative abundance of taxa in the top deciles and their dynamics are illustrated in Figure 4. The results of the entire microbial community are reported in 
supplementary information (Fig S3). The overall changes in microbial composition were evaluated with PCoA analysis showing that the differences caused by the bioaugmentation process were significant (Fig. S4). More specifically, the vast majority of the taxa in mesophilic granules decreased significantly in relative abundance demonstrating inability to survive at thermophilic conditions (Fig. 4, Group1). For example, genus $T 78$ decreased from $33.3 \%$ to less than $10 \%$ in both reactors indicating that the transition to thermophilic temperature created a hostile habitat to this taxon. Previous research evidenced that $T 78$ was a dominant microbe in mesophilic potato juice digesting granules [35] and was postulated to be responsible for the maintenance of sludge granular structure $[13,36]$. Nevertheless, in this experiment the granules maintained their structures even after the significant decrease of genus $T 78$ suggesting that besides the filamentous morphology of living cells, $T 78$ could probably produce extracellular polymers responsible for the granular structure maintenance [37]. Meantime we also speculate that other thermophiles harbouring a similar property emerged during temperature transition and kept the granules intact.

A cluster of taxa increased significantly in abundance regardless of bioaugmentation process, suggesting that their proliferation was due to the increase of operational temperature (Fig. 4, Group 2). Among those taxa, genus $S 1$ underwent the most substantial increase and its relative abundance reached $20 \%$ of the total community. This result becomes even more interesting considering that $S 1$ was almost absent at mesophilic conditions. The sequence of the most representative OTU of this taxon was $99 \%$ similar to Defluviitoga tunisiensis, which is a thermophilic fermentative bacterium [38]. The same species was previously found to be dominant in liquid phase of UASB reactor and was suggested to be closely related to thermophilic degradation of potato juice [12]. Regarding the archaeal community, OTUs similar to Methanoculleus and Methanosarcina increased significantly in abundance under thermophilic conditions, even though being in extremely low abundance during mesophilic operation. Although the sequence of OTU identified as Methanosarcina was 100\% 
similar to $M$. thermophila, no significant difference was observed between samples with bioaugmentation (TA) and control (Control 2). This result suggested that the increase in abundance of this specific methanogen was related to temperature adaptation rather than bioaugmentation. As it will be further discussed, the better performance of the bioaugmented reactor was mainly attributed to the increased abundance of other archaeal species.

Some taxa were not influenced by the temperature conditions and were found abundant both under mesophilic and thermophilic operations (Fig. 4, Group 3). Archaea similar to Methanolinea were found within this group and the corresponding OTU was $98 \%$ similar to Methanolinea tarda. The type strain of this taxon was reported to form multicellular filaments longer than $8 \mu \mathrm{m}$ promoting its evolvement in granular structures [39]. Furthermore, the wide temperature range of M. tarda (35 to $\left.55^{\circ} \mathrm{C}\right)$ growth also allows it to grow in both mesophilic and thermophilic conditions. Methanolinea was the second most abundant archaeal taxon found in granules after Methanobacterium beijingense. Since $M$. beijingense was previously proven unable to perform methanogenesis under thermophilic conditions, Methanolinea spp. probably played an important role in restoring methanogenic activity after the temperature transition in both bioaugmented and control reactors.

Comparing the microbial profiles of the granules obtained from the two reactors (i.e. with TA or Control 2), several taxa were promoted to grow by the bioaugmentation (Fig. 4, Group 4). $M$. thermautotrophicus presented approximately 2.5 folds higher relative abundance in TA compared to the Control 2 indicating that the injected $M$. thermautotrophicus was successfully retained by granular structures. Besides, the growth of some indigenous bacteria was also promoted probably due to their syntrophic interaction with this archaeon. For example, species related to Thermacetogenium were observed to be 2.2 folds higher in TA compared to Control 2 and the representative OTU was $94 \%$ similar to a thermophilic syntrophic acetate oxidizer namely 
Thermacetogenium phaeum [40]. Moreover, Syntrophobacter spp. were also found 2.2 folds higher in TA and the BLAST results identified this taxon to be $95 \%$ similar to Syntrophobacter wolinii, which is a syntrophic propionate-degrading bacterium [41].

\section{Conclusions}

The current study demonstrated that bioaugmentation can be an efficient method to facilitate an operational temperature transition from mesophilic to thermophilic conditions, and thus, is proposed as an alternative strategy to rapidly start up thermophilic UASB reactors. More specifically, the injection of axenic methanogenic culture into a UASB reactor was identified as the most promising microbial adaptation strategy. A remarkable difference in the microbial profile due to temperature transition was demonstrated and mild but significant changes were highlighted between the applied bioaugmentation strategies. The exogenous hydrogenotrophic methanogen was observed to be encapsulated in the pre-existing granular structures during bioaugmentation and concomitantly promoted the growth of syntrophic fatty acid oxidizers. Finally, the bioaugmented granular community was responsible for a persistent higher methane production rate compared to the control reactor.

\section{Acknowledgement}

We thank Hector Garcia and Hector Diaz for technical assistance. X. Zhu acknowledges the financial support provided by the Integrated Water Technology (InWaTech) project, research collaboration between the Technical University of Denmark and the Korean Advanced Institute of Science and Technology (DTU-KAIST, http://www.inwatech.org). This work was supported by the Danish Council for Strategic Research under the project "SYMBIO - Integration of biomass and wind power for biogas enhancement and upgrading via hydrogen assisted anaerobic digestion”, 
contract 12-132654. Illumina sequencing was performed at the Ramaciotti Centre for Genomics

(Sydney, Australia).

\section{Reference}

[1] H.S. Shin, J.H. Youn, Conversion of food waste into hydrogen by thermophilic acidogenesis, Biodegradation. 16 (2005) 33-44.

[2] C. Rico, N. Muñoz, J. Fernández, J.L. Rico, High-load anaerobic co-digestion of cheese whey and liquid fraction of dairy manure in a one-stage UASB process: limits in cosubstrates ratio and organic loading rate, Chem. Eng. J. 262 (2015) 794-802.

[3] M. Senthilkumar, G. Gnanapragasam, V. Arutchelvan, S. Nagarajan, Treatment of textile dyeing wastewater using two-phase pilot plant UASB reactor with sago wastewater as cosubstrate, Chem. Eng. J. 166 (2011) 10-14.

[4] X. Lu, G. Zhen, A.L. Estrada, M. Chen, J. Ni, T. Hojo, K. Kubota, Y.-Y. Li, Operation performance and granule characterization of upflow anaerobic sludge blanket (UASB) reactor treating wastewater with starch as the sole carbon source, Bioresour. Technol. 180 (2015) 264-273.

[5] S. Chong, T.K. Sen, A. Kayaalp, H.M. Ang, The performance enhancements of upflow anaerobic sludge blanket (UASB) reactors for domestic sludge treatment--a state-of-the-art review., Water Res. 46 (2012) 3434-70.

[6] C. Fang, K. Boe, I. Angelidaki, Biogas production from potato-juice, a by-product from potato-starch processing, in upflow anaerobic sludge blanket (UASB) and expanded granular sludge bed (EGSB) reactors, Bioresour. Technol. 102 (2011) 5734-5741.

[7] J. Fernández-Rodríguez, M. Pérez, L.I. Romero, Comparison of mesophilic and thermophilic dry anaerobic digestion of OFMSW: kinetic analysis, Chem. Eng. J. 232 (2013) 59-64.

[8] C.S. Hwu, G. Lettinga, Acute toxicity of oleate to acetate-utilizing methanogens in mesophilic and thermophilic anaerobic sludges, Enzyme Microb. Technol. 21 (1997) 297301.

[9] H. Fang, I. Lau, Startup of thermophilic (55UC) UASB reactors using different mesophilic seed sludges, Water Sci. Technol. 34 (1996) 445-452.

[10] K. Syutsubo, H. Harada, A. Ohashi, H. Suzuki, An effective start-up of thermophilic uasb reactor by seeding mesophilically-grown granular sludge, Water Sci. Technol. 36 (1997) 391-398.

[11] M. Khemkhao, B. Nuntakumjorn, S. Techkarnjanaruk, C. Phalakornkule, UASB performance and microbial adaptation during a transition from mesophilic to thermophilic treatment of palm oil mill effluent., J. Environ. Manage. 103 (2012) 74-82.

[12] X. Zhu, L. Treu, P.G. Kougias, S. Campanaro, I. Angelidaki, Characterization of the 
planktonic microbiome in upflow anaerobic sludge blanket reactors during adaptation of mesophilic methanogenic granules to thermophilic operational conditions, Anaerobe. (2017).

[13] X. Zhu, P.G. Kougiasa, L. Treu, S. Campanaro, I. Angelidaki, Microbial community changes in methanogenic granules during the transition from mesophilic to thermophilic conditions, Appl. Microbiol. Biotechnol. (2017).

[14] P. Tsapekos, P.G. Kougias, S.A. Vasileiou, L. Treu, S. Campanaro, G. Lyberatos, I. Angelidaki, Bioaugmentation with hydrolytic microbes to improve the anaerobic biodegradability of lignocellulosic agricultural residues, Bioresour. Technol. (2017).

[15] I.A. Fotidis, H. Wang, N.R. Fiedel, G. Luo, D.B. Karakashev, I. Angelidaki, Bioaugmentation as a solution to increase methane production from an ammonia-rich substrate, Environ. Sci. Technol. 48 (2014) 7669-7676.

[16] V.P. Tale, J.S. Maki, D.H. Zitomer, Bioaugmentation of overloaded anaerobic digesters restores function and archaeal community, Water Res. 70 (2015) 138-147.

[17] F.-B. Yu, S.W. Ali, L.-B. Guan, S.-P. Li, S. Zhou, Bioaugmentation of a sequencing batch reactor with Pseudomonas putida ONBA-17, and its impact on reactor bacterial communities, J. Hazard. Mater. 176 (2010) 20-26.

[18] I. Angelidaki, S.P. Petersen, B.K. Ahring, Effects of lipids on thermophilic anaerobicdigestion and reduction of lipid inhibition upon addition of bentonite, Appl. Microbiol. Biotechnol. 33 (1990) 469-472.

[19] P. Kongjan, O. Sompong, I. Angelidaki, Performance and microbial community analysis of two-stage process with extreme thermophilic hydrogen and thermophilic methane production from hydrolysate in UASB reactors, Bioresour. Technol. 102 (2011) 4028-4035.

[20] M.R. Smith, R.A. Mah, Growth and methanogenesis by Methanosarcina strain 227 on acetate and methanol, Appl. Environ. Microbiol. 36 (1978) 870-879.

[21] APHA, Standard Methods for the Examination of Water and Wastewater, American Public Health Association., 2005. doi:10.2105/AJPH.51.6.940-a.

[22] P.G. Kougias, K. Boe, E.S. Einarsdottir, I. Angelidaki, Counteracting foaming caused by lipids or proteins in biogas reactors using rapeseed oil or oleic acid as antifoaming agents, Water Res. 79 (2015) 119-127.

[23] I. Angelidaki, D.J. Batstone, Anaerobic Digestion: Process, in: Solid Waste Technol. Manag., Chichester, West Sussex, UK : Wiley, 2011: pp. 583-600.

[24] P.G. Kougias, L. Treu, D.P. Benavente, K. Boe, S. Campanaro, I. Angelidaki, Ex-situ biogas upgrading and enhancement in different reactor systems, Bioresour. Technol. 225 (2017) 429-437.

[25] J. Oksanen, F.G. Blanchet, R. Kindt, P. Legendre, P.R. Minchin, R.B. O'hara, G.L. Simpson, P. Solymos, M.H.H. Stevens, H. Wagner, Package "vegan," Community Ecol. Packag. Version. 2 (2013).

[26] D.H. Parks, G.W. Tyson, P. Hugenholtz, R.G. Beiko, STAMP: statistical analysis of 
taxonomic and functional profiles, Bioinformatics. 30 (2014) 3123-3124.

[27] A.I. Saeed, V. Sharov, J. White, J. Li, W. Liang, N. Bhagabati, J. Braisted, M. Klapa, T. Currier, M. Thiagarajan, TM4: a free, open-source system for microarray data management and analysis, Biotechniques. 34 (2003) 374.

[28] M. Johnson, I. Zaretskaya, Y. Raytselis, Y. Merezhuk, S. McGinnis, T.L. Madden, NCBI BLAST: a better web interface, Nucleic Acids Res. 36 (2008) W5-W9.

[29] L.W.H. Pol, S.I. de Castro Lopes, G. Lettinga, P.N.L. Lens, Anaerobic sludge granulation, Water Res. 38 (2004) 1376-1389.

[30] D. Yu, J. Liu, Q. Sui, Y. Wei, Biogas-pH automation control strategy for optimizing organic loading rate of anaerobic membrane bioreactor treating high COD wastewater, Bioresour. Technol. 203 (2016) 62-70.

[31] A.L.A. Soh, H. Ralambotiana, B. Ollivier, G. Prensier, E. Tine, J.-L. Garcia, Clostridium thermopalmarium sp. nov., a moderately thermophilic butyrate-producing bacterium isolated from palm wine in Senegal, Syst. Appl. Microbiol. 14 (1991) 135-139.

[32] D.G. Zavarzina, T.N. Zhilina, T.P. Tourova, B.B. Kuznetsov, N.A. Kostrikina, E.A. BonchOsmolovskaya, Thermanaerovibrio velox sp. nov., a new anaerobic, thermophilic, organotrophic bacterium that reduces elemental sulfur, and emended description of the genus Thermanaerovibrio., Int. J. Syst. Evol. Microbiol. 50 (2000) 1287-1295.

[33] M. Lenz, A.M. Enright, V. O'Flaherty, A.C. van Aelst, P.N.L. Lens, Bioaugmentation of UASB reactors with immobilized Sulfurospirillum barnesii for simultaneous selenate and nitrate removal, Appl. Microbiol. Biotechnol. 83 (2009) 377-388.

[34] V.P. Tale, J.S. Maki, C.A. Struble, D.H. Zitomer, Methanogen community structure-activity relationship and bioaugmentation of overloaded anaerobic digesters, Water Res. 45 (2011) 5249-5256.

[35] P. Antwi, J. Li, P.O. Boadi, J. Meng, E. Shi, C. Xue, Y. Zhang, F. Ayivi, Functional bacterial and archaeal diversity revealed by $16 \mathrm{~S}$ rRNA gene pyrosequencing during potato starch processing wastewater treatment in an UASB, Bioresour. Technol. (2017).

[36] H. Satoh, Y. Miura, I. Tsushima, S. Okabe, Layered structure of bacterial and archaeal communities and their in situ activities in anaerobic granules, Appl. Environ. Microbiol. 73 (2007) 7300-7307.

[37] Y. Liu, H.-L. Xu, S.-F. Yang, J.-H. Tay, Mechanisms and models for anaerobic granulation in upflow anaerobic sludge blanket reactor, Water Res. 37 (2003) 661-673.

[38] W. Ben Hania, R. Godbane, A. Postec, M. Hamdi, B. Ollivier, M.-L. Fardeau, Defluviitoga tunisiensis gen. nov., sp. nov., a thermophilic bacterium isolated from a mesothermic and anaerobic whey digester, Int. J. Syst. Evol. Microbiol. 62 (2012) 1377-1382.

[39] H. Imachi, S. Sakai, Y. Sekiguchi, S. Hanada, Y. Kamagata, A. Ohashi, H. Harada, Methanolinea tarda gen. nov., sp. nov., a methane-producing archaeon isolated from a methanogenic digester sludge, Int. J. Syst. Evol. Microbiol. 58 (2008) 294-301. 
[40] S. Hattori, Y. Kamagata, S. Hanada, H. Shoun, Thermacetogenium phaeum gen. nov., sp. nov., a strictly anaerobic, thermophilic, syntrophic acetate-oxidizing bacterium., Int. J. Syst. Evol. Microbiol. 50 (2000) 1601-1609.

[41] D.R. Boone, M.P. Bryant, Propionate-degrading bacterium, Syntrophobacter wolinii sp. nov. gen. nov., from methanogenic ecosystems, Appl. Environ. Microbiol. 40 (1980) 626-632. 


\section{Tables}

Table 1 Characteristics of the potato juice

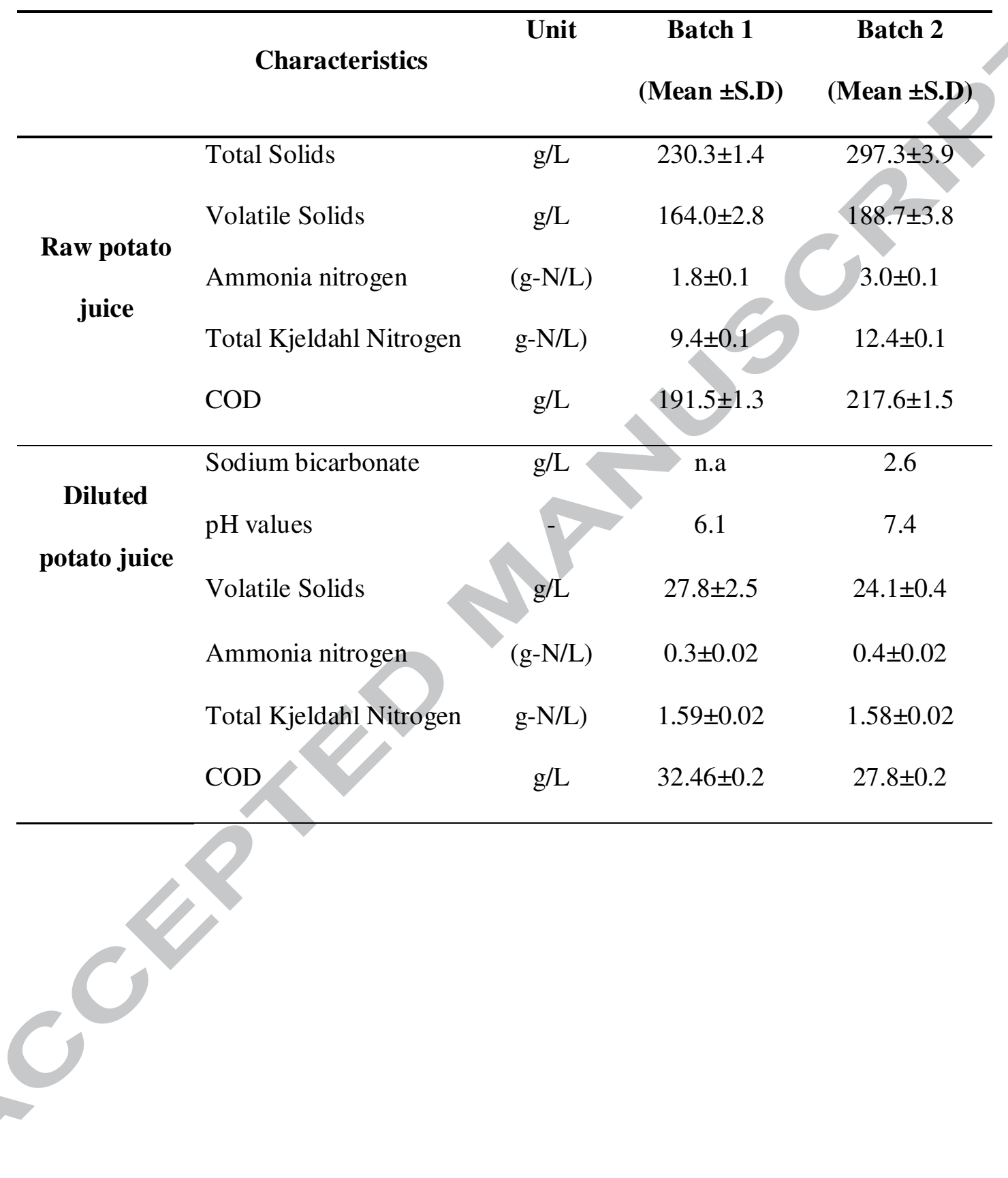


Table 2 Operation details of all reactors in both experiments.

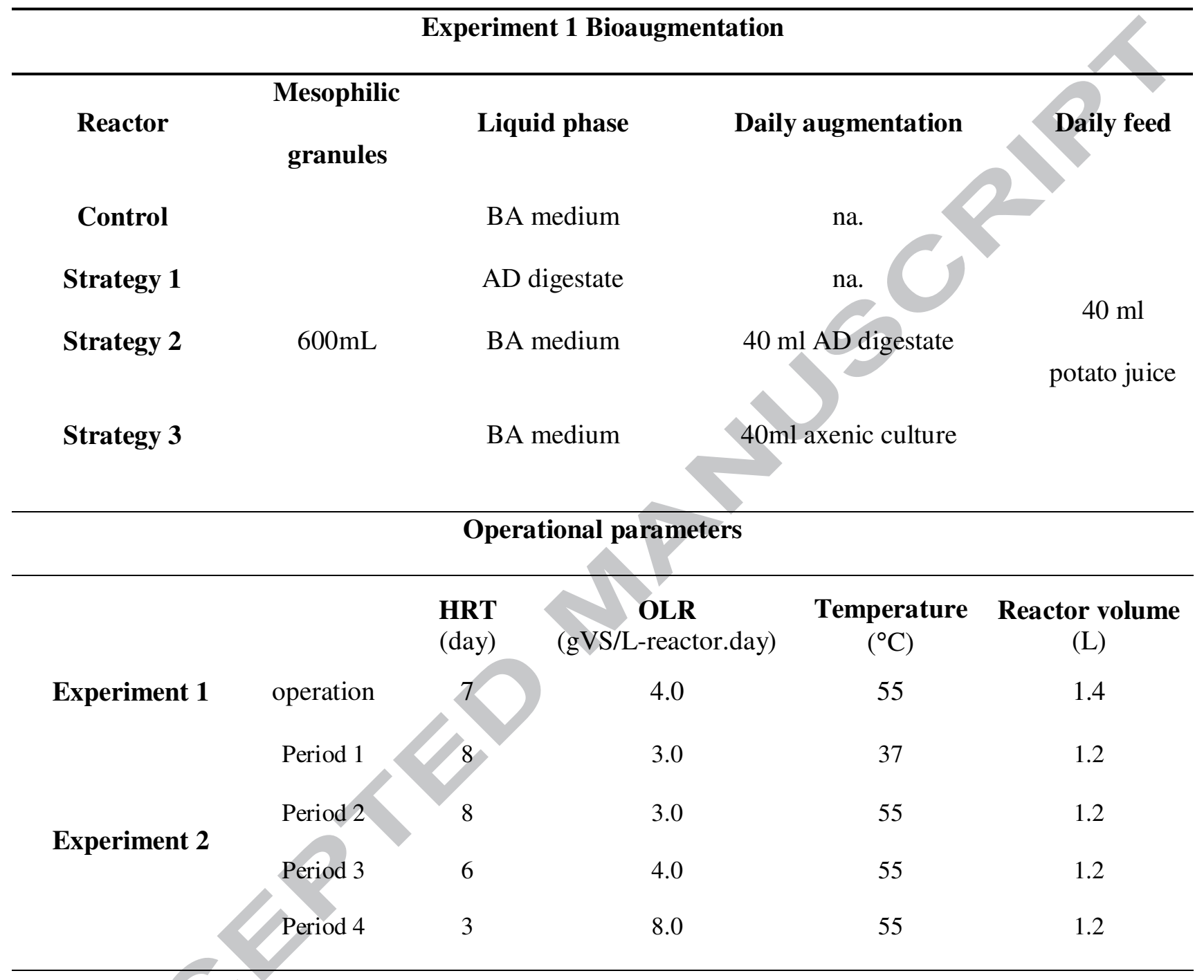




\section{Figures}

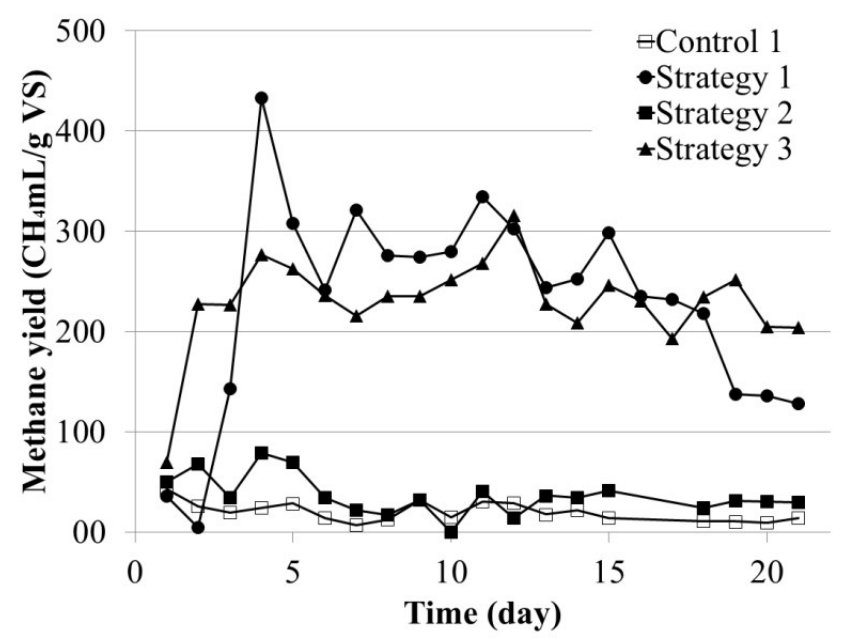

(a)

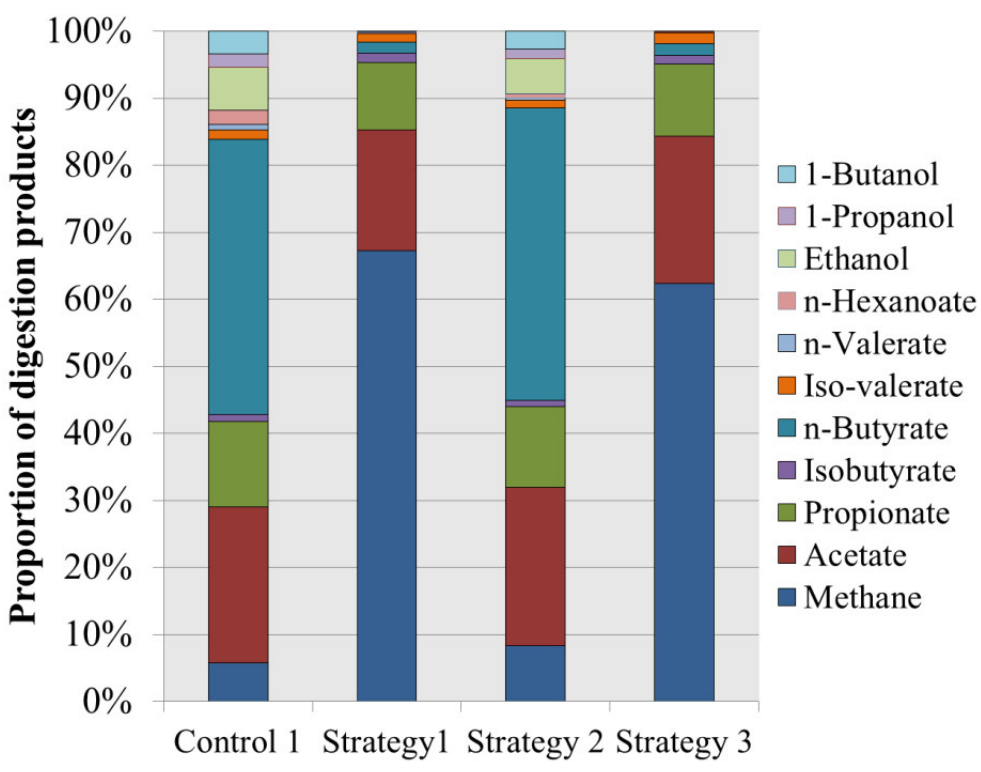

(b)

Fig. 1 Reactor performance for the different bioaugmentation strategies. a) Methane production yields after bioaugmentation b) Methane, VFAs and alcohol compositions at day 21 . 


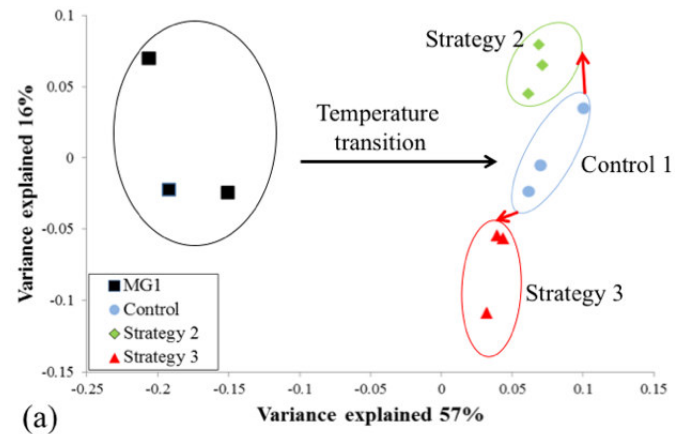

(a)

(b)
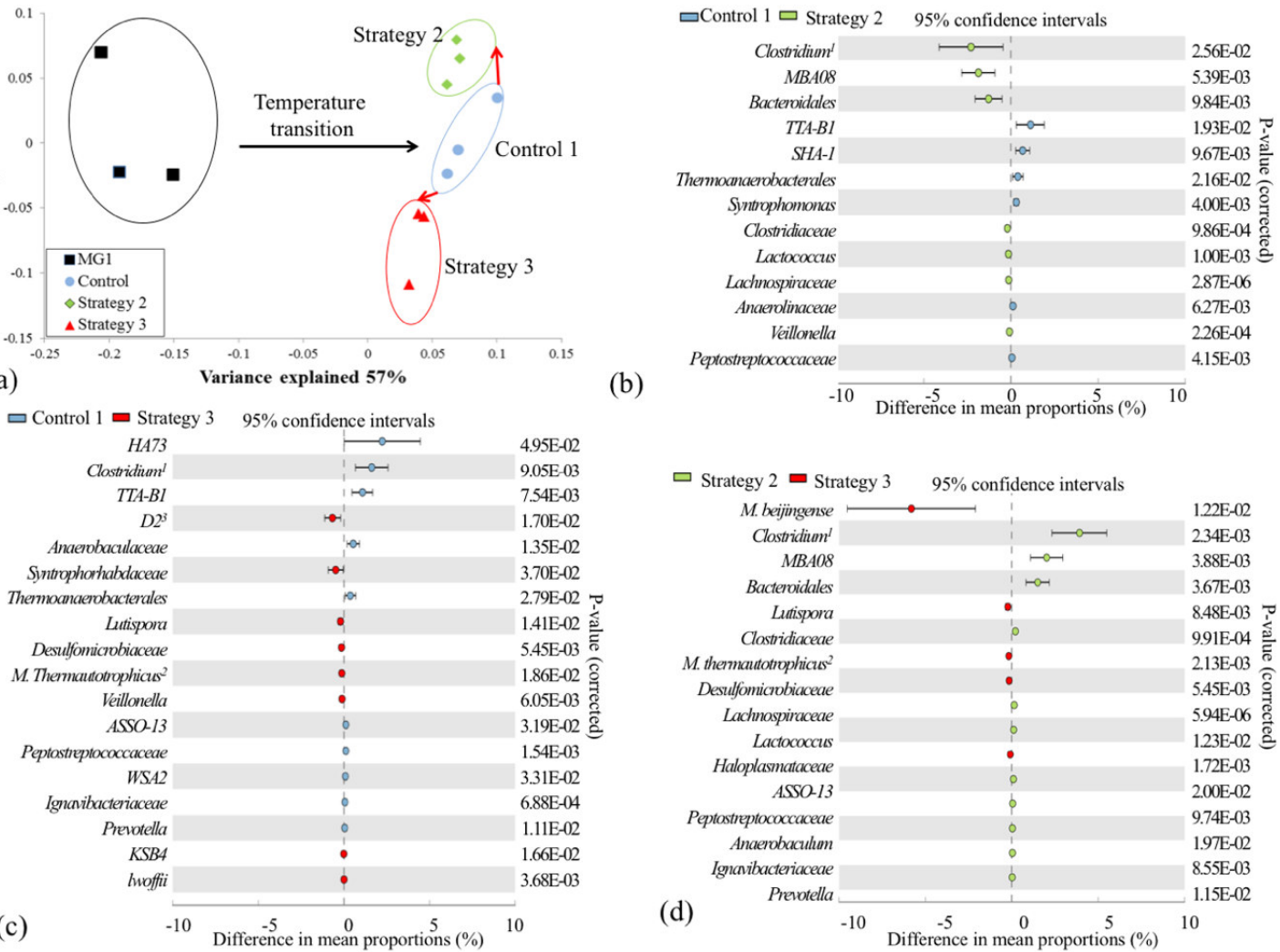

Fig.2 Microbial community composition shifts after the different bioaugmentation strategies. a)

PCoA based on Bray-Curtis dissimilarity distance showed distinct communities in mesophilic granules (MG) and thermophilic granules (Control, Strategy 1 and Strategy 2. b-d) Taxa presenting in significantly different relative abundance under the applied conditions (t-test). BLAST assignment of representative OTUs in selected taxa was marked with superscript notes: 1 Clostridium thermopalmarium, 2 Methanothermobacter thermautotrophicus and 3

Thermanaerovibrio velox 


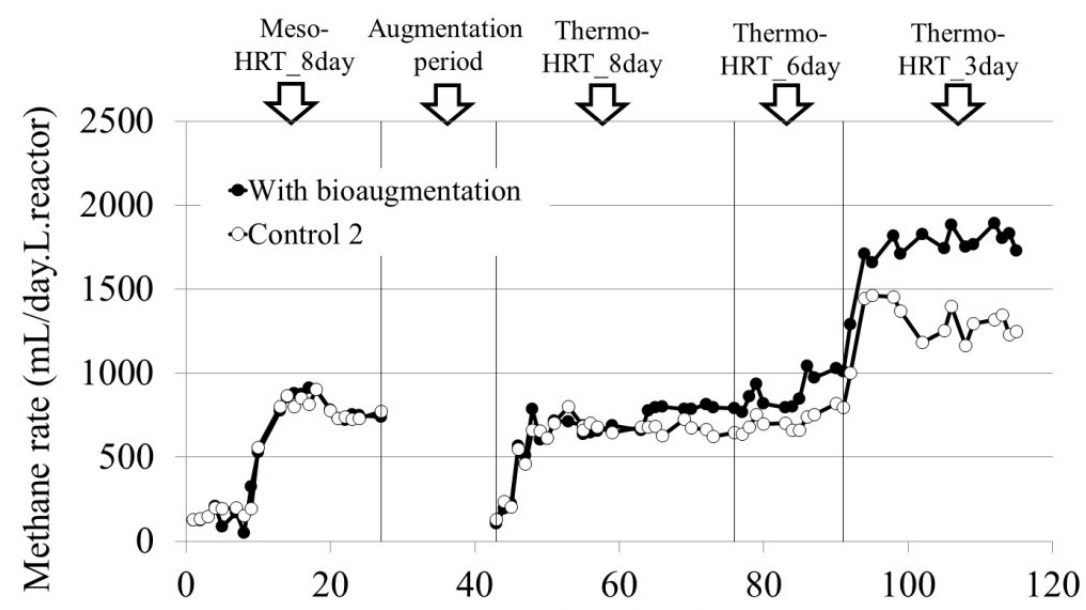

(a)

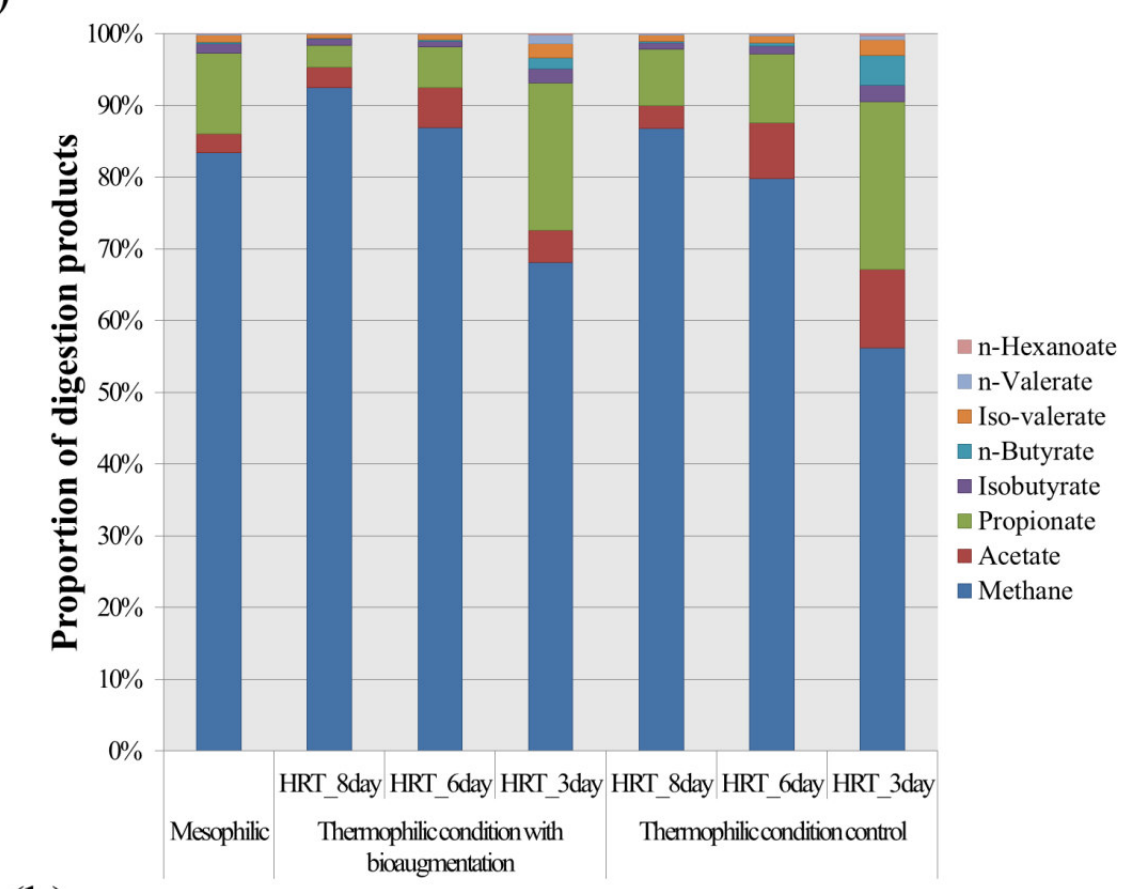

(b)

Fig. 3. Methane production under mesophilic and thermophilic condition. a) Methane production rates under mesophilic and thermophilic condition and bioaugmentation benefited biomethanation process. b) Methane is the main digestion product in all experimental phases (mesophilic, thermophilic with and without bioaugmentation) and the proportion of methane decreased with shorter HRT. 


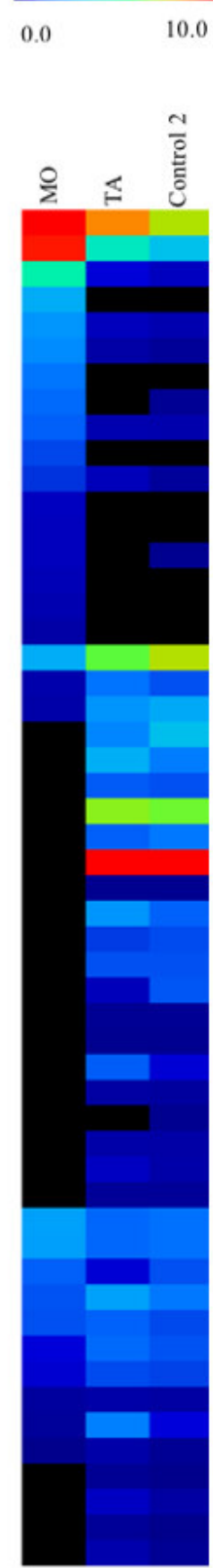

(a) $\begin{array}{lll}-2.0 & 0.0 & 2.0\end{array}$

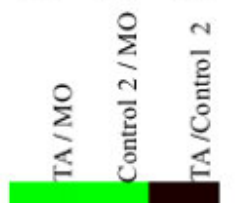

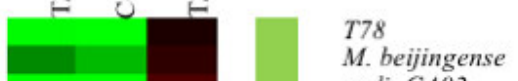

vadinCAO2

Sedimentibacter

Veillonellaceae

Clostridiales

Tissierella Soehngenia

Pseudomonas

Syntrophomonas

W22

SHD-231

vadin $\mathrm{HB} 04$

Helicobacteraceae

Alcaligenaceae

RB046

Lachnospiraceae

Acinetobacter

D2

Lutispora

Clostridiaceae

MBA08

Thermoanaerobacterales

OPB54

Anaerobaculum

SHA-98

$S 1$ [Defluviitoga funisiensis]

TIBDII

Clostridium

Caldicoprobacter

Thermoanaerobacteraceae

Tepidimicrobium

Methanosarcina [Methanosarcina thermophila]

ML615J-28

A55 D2I

Peptococcaceae

Campylobacteraceae

Clostridia

Tissierellaceae

Methanoculleus

E6

HA73

Treponema

Anaerobrancaceae

SHA-1

Syntrophorhabdaceae

DCE29

Methanolinea [Methanolinea tarda]

Syntrophobacter [Syntrophobacter wolinii]

+ Ruminococcus

을 MBNT15

Thermacetogenium [Thermacefogenium phaeum]

$M$. thermautotrophicus

Moorella

(b) 
Fig. 4 Microbial community composition in mesophilic granules (MO), thermophilic granules with bioaugmentation (TA) and thermophilic control granules (Control 2). Correspondence between colours and relative abundance/ folds change is reported in the top scale (a) Relative abundance of selected taxa identified in top deciles of the total community. (b) Fold change (log2) of relative abundance for selected taxa. Group 1: Mesophiles decreased in relative abundance regardless of bioaugmentation. Group 2: thermophiles increased in relative abundance regardless of bioaugmentation. Group 3: Taxa not influenced by the temperature conditions. Group 4: Taxa proliferated by bioaugmentation. BLAST assignment of representative OTUs in selected taxa were presented in grey parentheses. 


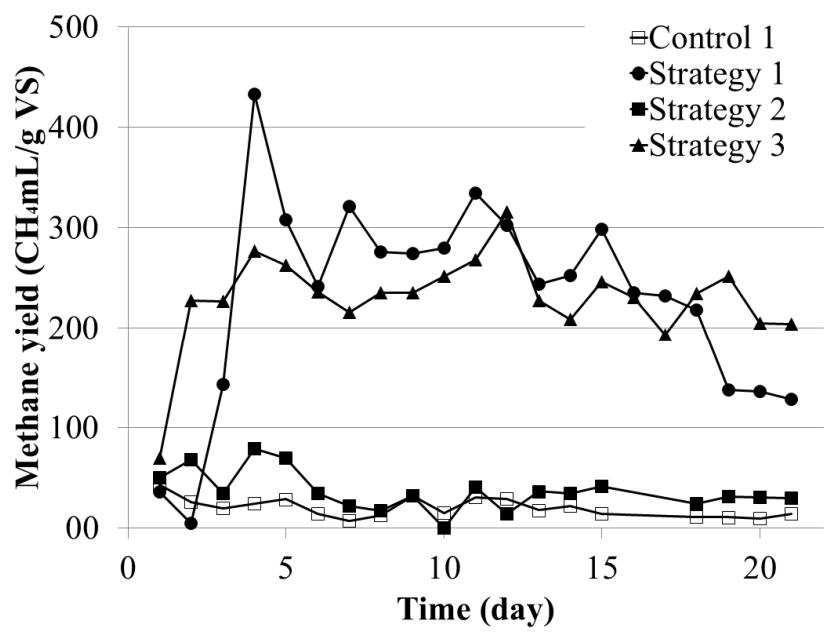

(a)

Time (day)

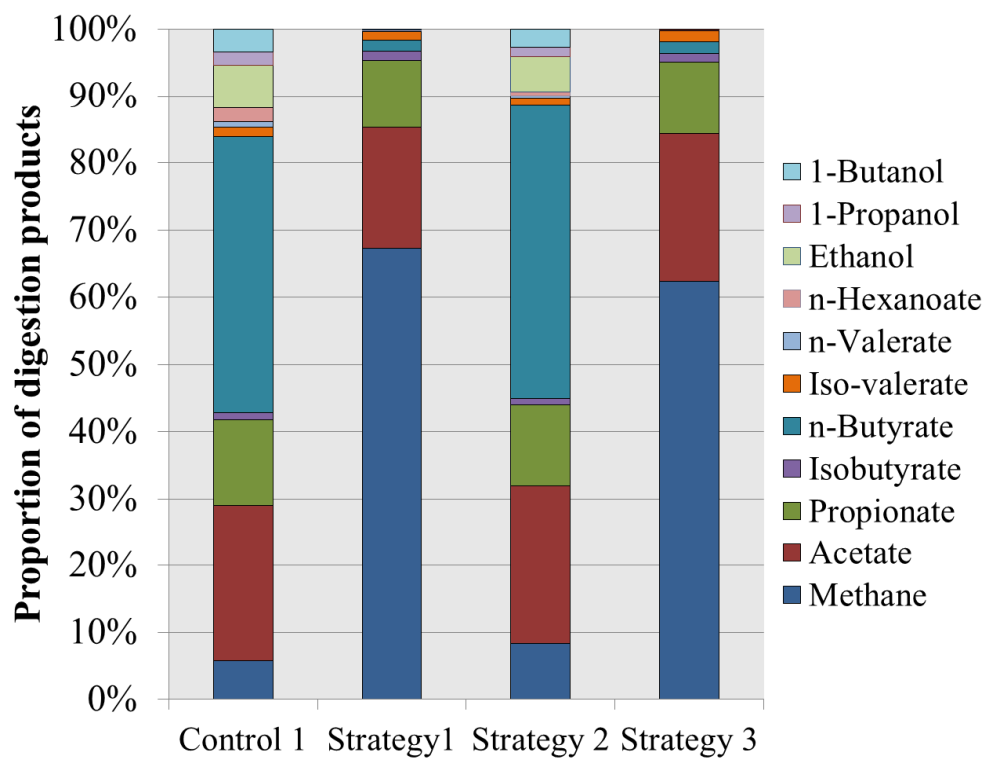

(b) 


\section{ACCEPTED MANUSCRIPT}

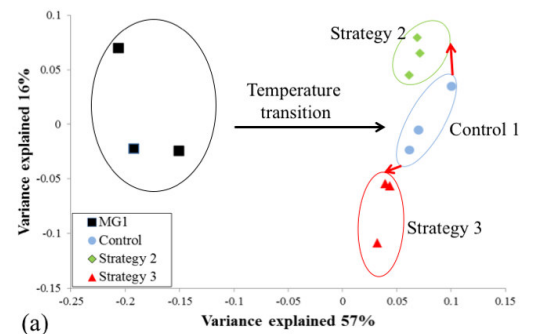

(a)

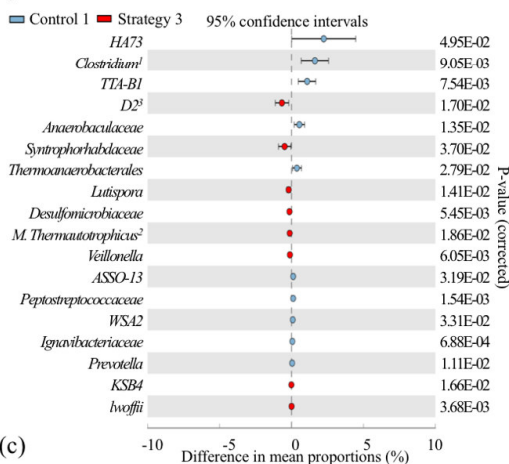

(b)

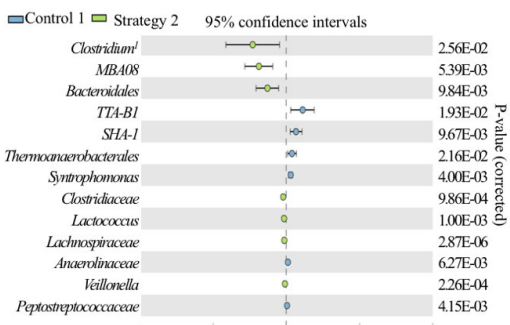

$\begin{array}{lll}-10 & \text { Difference in mean proportions }(\%) & 10\end{array}$

ㅁ Strategy $2=$ Strategy $3 \quad 95 \%$ confidence intervals

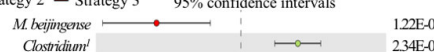

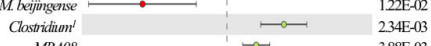

$\begin{array}{r:rr}\text { MBAD8 } & 3.88 \mathrm{E}-03 \\ \text { Bacteridales } & 3.67 \mathrm{E}-03\end{array}$

Lutispora $\quad \vdots \quad 8.48 \mathrm{E}-03$

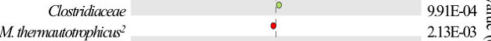

Desuffomicobiciceae $\quad \vdots \quad 5.45 \mathrm{E}-03$

$\begin{array}{rr}\text { Lachnospiraceae } & 594 \mathrm{E}-06 \\ \text { Lactococals } & 1.23 \mathrm{E}-02\end{array}$

$\begin{array}{lll}\text { Haloplasmatceeae } & - & 1.72 \mathrm{E}-03\end{array}$

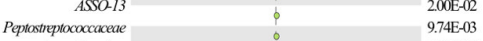

Anaerobacautan $\quad ! \quad 197 \mathrm{E}-\mathrm{C}$

(d)

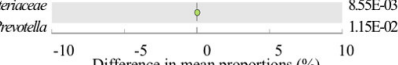

$-10 \begin{gathered}-5 \\ \text { Difference in mean proportions }\end{gathered}$ 


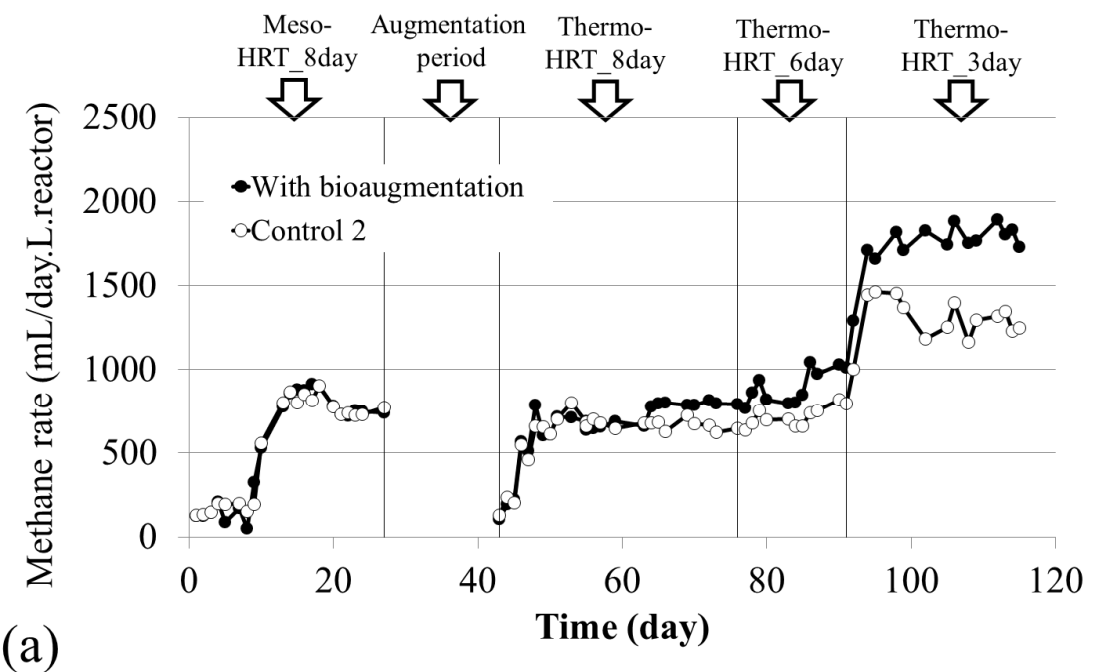

(a)

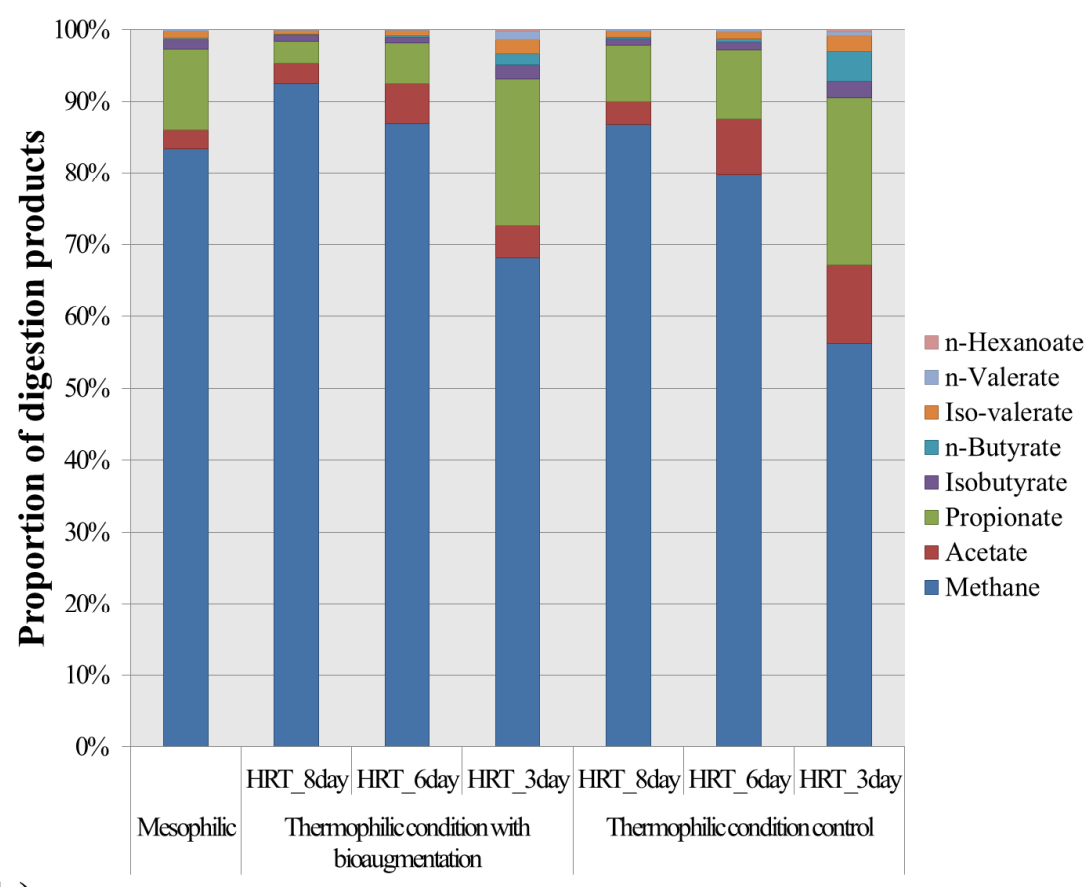

(b) 


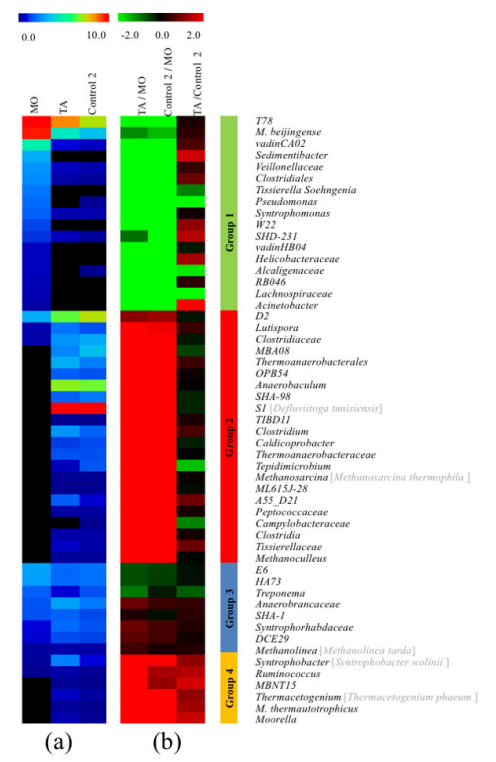


- Injection of axenic methanogens benefits temperature transition of UASB reactors

- Exogenous hydrogenotrophic methanogen can be confined to pre-existing granules

- Bioaugmentation promoted the growth of syntrophic acid oxidizers in granules

- Bioaugmented reactor produced maximum $40 \%$ more methane than abiotic augmentation

\footnotetext{
- Bioaugmented reactor produced maximum $40 \%$ more methane than abiotic augmentation
} 